\title{
Provocações de agentes tecnológicos como artistas
}

Fábio Oliveira Nunes*

RESUMO: O presente artigo propõe uma reflexão sobre processos miméticos que envolvem a atribuição do status de artista a agentes tecnológicos seja emulando o gesto artístico - quando robôs simulam a prática de pintura e desenho - ou assumindo personas criadoras - quando artistas criam personas supostamente com algum poder de criação disseminando-as através das redes digitais. Estas propostas ocupam-se de uma desmitificação crítica do fazer artístico, questionando a figura emblemática do criador ou o seu discurso. Em proximidade a estas reflexões, temos a experimentação de Mimo Steim, onde um suposto artista tecnológico baseado em Linguagem de Marcação de Inteligência Artificial (AIML) conversa com visitantes na web.

Palavras-chave: mimetismo, autômatos, web arte, inteligência artificial.

ABSTRACT: This paper proposes a reflection on mimetic processes that involve the attribution of the artist status to technological agents that emulate the artistic gesture - when robots simulate the practice of painting and drawing - or becoming creator personas - when artists create personas with some supposedly creating power disseminating them through digital

* Fábio Oliveira Nunes é doutor em Artes pela Universidade de São Paulo e pesquisador em pós-doutorado no Instituto de Artes da Universidade Estadual Paulista, com apoio da Fundação de Amparo à Pesquisa do Estado de São Paulo. E-mail: fabiofon@gmail.com. 
networks. These proposals are concerned with a critic demystification of the art making, the emblematic figure of the creator or his speech. In proximity to these reflections, we got the Mimo Steim experimentation, where a supposed technological artist based on Artificial Intelligence Markup Language (AIML) talks to visitors on the web.

Keywords: mimicry, robots, web art, artificial intelligence.

\section{Em vez de criar objetos, criar artistas}

Com a provocação comum aos manifestos de vanguarda e ironicamente decretando o "fim definitivo e oficial" da arte tal como a conhecemos, em 2004, o artista português dos novos meios Leonel Moura defende, a partir de seu Manifesto da Arte Simbiótica, uma nova condição: o surgimento de um "artista simbiótico", um novo paradigma para o artista contemporâneo, que deixaria de produzir diretamente produtos artísticos para criar agentes artificiais devotados às artes (MOURA e PEREIRA, 2004) - em outras palavras, em vez de realizar diretamente objetos artísticos, criar artistas. O ponto de vista de Moura pode ser contextualizado através de seu significativo percurso no desenvolvimento de autômatos com habilidade de criar imagens gráficas e pictóricas como o RAP - Robotic Action Painter - um pequeno robô equipado com canetas coloridas, sensores e programação capazes de compreender cores e padrões ${ }^{1}$. Desconsiderando a provocação de Moura, que implica reduzir o ato da criação apenas a resultados plásticos, sua constatação de uma condição em que "artistas que criam artistas" é bastante satisfatória para pensarmos em incursões que atribuem o status de artista a outros agentes, envolvendo alguma alteridade - de ação e/ou personalidade. Esses agentes se caracterizam por um desprendimento da figura do artista que os cria, descolamento proporcionado pelas novas tecnologias através de dispositivos robóticos, sistemas de inteligência artificial, disseminação em redes digitais, entre outras muitas possibilidades.

Em um trabalho anterior (NUNES, 2012a), constatamos uma estratégia recorrente em diversos trabalhos de arte e tecnologia: a tentativa de assumir características de equivalentes de outros contextos, criando ações que exploram a ambiguidade e a indistinção entre "verdadeiro" e 
"falso." Percebem-se incursões que se caracterizam por algum grau de imitação envolvida em uma relação sistêmica, o que nos permite a aproximação com a ideia de mimetismo. Na natureza, essa seria uma condição constituída de três elementos: o padrão (modelo), o imitante (espécie mimética) e um receptor do sinal, ou seja, aquele que pode não encontrar distinção segura entre o padrão e o imitador. (BARETT apud GEBAUER e WULF, 2004, p. 40)

Ao nos aproximarmos da proposta dessa "criação de artistas", percebemos que há aqui também um desejo mimético em curso: um modelo que pode ser um artista moderno ou contemporâneo, um artista mimético que imita o modelo sob algum aspecto e, claro, o público que se depara com uma indistinção não explícita: as obras de agentes robóticos podem se passar por objetos artísticos humanos, assim como personas criadoras podem ser entendidas como artistas plenos. Essas propostas em diferentes graus ocupam-se de uma desmitificação crítica do próprio fazer artístico, da figura emblemática do criador ou do seu discurso. É importante constatar que essas propostas estão envolvidas em relações sistêmicas estabelecidas, notadamente, relacionais, que podem envolver o sistema da arte (e seus espaços institucionalizados), as expectativas do público sobre o artista/a obra e o diálogo com a produção contemporânea. Partindo dessas premissas, nas próximas linhas nos ocuparemos de duas situações: agentes tecnológicos que imitam a ação do fazer artístico em si e a difusão de personas que se passam por artistas nas redes digitais. Em ambas as situações, há ato de eleger como "artista" - seja pela ação, seja pela persona - um agente com certa alteridade, baseado em tecnologias digitais.

\section{Agentes que assumem a ação}

Uma importante incursão antecedente a essa discussão é realizada pelo artista suíço Jean Tinguely que, conhecido por suas máquinas que satirizam o otimismo tecnológico e científico do pós-guerra no século XX, cria máquinas que imitam o gesto espontâneo do expressionismo abstrato. Em Metamatics (1955-1959), Tinguely cria metaobras: máquinas que criam automaticamente sequências infinitas de desenhos, baseadas em engrenagens, rodas, correias e motores; por conta de imperfeições nos mecanismos, seus desenhos nunca são exatamente iguais, tal como o gesto humano. O objetivo do mecanismo dessas metaobras é criar copiosamente grafismos em folhas de papel. Analisadas conceitualmente, suas ações relativizam 
a figura do artista como gênio e, claro, estabelecem um diálogo fértil com as conquistas tecnológicas de seu período.

Há vários anos, coube a uma parcela dos artistas que adotaram a criação em meios tecnológicos a discussão sobre as relações instituídas entre homens e máquinas. Às engrenagens mecânicas outrora utilizadas porTinguely, somam-se novos dispositivos baseados em tecnologia digital, ampliando a potencialidade de experimentações. Ao mesmo tempo, à figura do robô, cada vez mais difundida no imaginário, pode se associar uma crescente e inevitável tomada dos papéis originalmente humanos por equivalentes maquínicos ${ }^{2}$ - em um cenário que condiciona os humanos à produtividade das máquinas e as máquinas à subjetividade dos humanos.

A constante redefinição daquilo que é de domínio humano será fundamental na produção de artistas como o espanhol Carlos Corpa, que se preocupa em envolver robôs em situações que são consideradas essencialmente humanas. Em 1992, Corpa realizou uma instalação baseada em uma tórrida cena de sexo entre robôs, chamada de El sexo en las máquinas. Em 2007, criou Sufrobot, um robô que "sofre crises de ansiedade", gritando e tornando-se assustadoramente agitado quando percebe a presença de humanos através de seu sistema de visão artificial. E ainda criou o robô-poeta-pedinte PaCo - Poeta Automático Callejero Online (2004), em conjunto com Ana María Garcia-Serrado da Universidade Politécnica de Madrid, que se locomove em uma cadeira de rodas e produz poemas ao receber moedas. O artista explicita os seus propósitos em seu Manifesto Pessoal: “Colocar máquinas em lugar de humanos, ali onde os humanos nunca esperariam ver uma máquina. Uma metáfora do mundo moderno. Nossa história de amor e ódio com a tecnologia". (CORPA apud GARCíA, 2013, p. 49) Ora, como esperado, esta é uma discussão que envolve também o fazer artístico como ato até então essencialmente humano: Corpa também cria robôs-artistas em APM - Another Painting Machine (1999) e Machina Artis 3.0 (2001)33, onde personagens robóticos pintam performaticamente superfícies a partir de uma programação aleatória.

Aos artistas que criam artistas, o fazer artístico pode ser visto basicamente sob dois aspectos: como uma atividade essencialmente intelectual - visão presente a partir da segunda metade do século XX, o artista como uma espécie de "sábio/filósofo/artesão" 4 - e como uma atividade em que se criam objetos essencialmente. Nicolas Bourriaud (2006, p. 136) é mais direto ao falar do artista na contemporaneidade: "o denominador comum entre todos os artistas é 
que mostram algo". E completa: "o fato de mostrar basta para definir o artista, se tratando de uma representação ou uma designação". Bem, já há algum tempo os robôs produzem objetos, ainda que não artísticos. Por sua vez, as máquinas de arte não só produzem como também "mostram" o que fazem - ocupam espaços de arte, como os museus. Com uma boa dose de provocação, Moura (2004) já insinua certa inferioridade da arte criada por humanos:

Quando a robótica deixou de simplesmente simular comportamentos humanos, como andar, jogar futebol ou contar anedotas, para se dedicar à realização da arte, alguma coisa de muito radical aconteceu. Robôs que fazem arte não questionam só a ideia de arte ou filosofia, mas põem em causa a nossa própria condição como humanos. Para que continuar a fazer algo que as máquinas fazem melhor e de forma mais consequente?

Ainda que necessariamente não compartilhem da proposição de Moura, podemos encontrar outras incursões de agentes tecnológicos como artistas. Sob o ponto de vista da linguagem, essas produções preocupam-se em imitar a prática artística em seu âmbito manual-motor: o gesto pictórico, o traço, a construção do desenho, oferecendo tanto resultados abstratos como também figurativos; mas, especialmente, operam com linguagens já consolidadas. Há, por exemplo, o robô do grupo alemão Robotlab na obra Autoportrait5 (2002): o autômato é capaz de realizar retratos humanos manipulando habilmente uma caneta diante de seus visitantes. Além de desenhar com grande fidelidade ao modelo, o robô ainda apresenta o resultado ao retratado ao final do trabalho. Já em Interactive Robotic Painting Machine (2011), do norte-americano Benjamin Grosser ${ }^{6}$, uma máquina robótica produz pinturas abstratas - algumas remetem à pintura a dedo - a partir de estímulos sonoros. Imitando uma expressividade pictórica que é peculiar aos humanos, certamente a natureza de suas criações passaria despercebida mesmo a olhares mais atentos.

Mas a criação por agentes tecnológicos não estará apenas restrita às linguagens mais tradicionais. Sem a pessoalidade própria dos robôs, o célebre trabalho Net.Art Generator7, desenvolvido desde 1997 pela artista alemã Cornelia Sollfrank e outros colaboradores, é também uma espécie de máquina de gerar arte baseada na World Wide Web - a interface gráfica da rede Internet. No decorrer dos anos, o trabalho já recebeu várias versões. A mais recente - a quinta versão, chamada de The Image Generator - gera automaticamente colagens digitais a partir da apropriação de imagens presentes na Internet, especialmente associadas a termos previamente dados pelo usuário. Ao coletar o material, o programa processa o conjunto com 
base em premissas aleatórias e combinadas. É inevitável associar o Net.Art Generator às incursões tecnológicas já citadas que imitam a prática do artista aqui atualizada ao universo da criação em novos meios. Mas não é só isso: há também um diálogo bem mais específico ao evocar uma estética "aleatória" das primeiras experimentações artísticas na web.

\section{Agentes que assumem personas}

Se, por um lado, temos várias incursões de agentes tecnológicos que assumem a prática comum aos artistas, por outro lado, é bastante recorrente o ato de "criar artistas" (fora do universo tecnológico) partindo de personas criadoras que envolverão uma condição de significativa alteridade. Ser um "outro" artista implica o exercício de uma nova identidade, buscando a noção de "ser artista" em um sentido muito mais existencial do que necessariamente prático. Há casos bastante conhecidos envolvendo personalidades como o poeta Fernando Pessoa - e seus conhecidos heterônimos - e o artista Marcel Duchamp - com Rrose Sélavy. Há ainda, mais recentemente, incursões como Marcelo do Campo e Marcelo Cidade, duas personas de artistas criadas pela artista brasileira Dora Longo Bahia, respectivamente em 2003 e 2010, para discutir o tema da identidade do artista contemporâneo, testando um dos mitos mais consolidados da arte moderna: o que associa a originalidade a um nome próprio. (FABRIS, 2012, p. 80) Então, no ato de atribuir a agentes tecnológicos o status de "artistas", cabe também pensar no potencial desses dispositivos para personificarem outros domínios da criação. Além da disposição em assumir o domínio manual-motor do fazer artístico, como pensar agentes que questionem também a pessoalidade, o pensamento, o discurso ou mesmo a identidade associada à figura do artista?

Com os novos meios - em especial, a rede Internet - que proporcionam contatos interpessoais à distância, torna-se facilitada a difusão de características que definem singularmente uma pessoa, diferentes daquelas que definiriam seus interlocutores em outros contextos. A interação através dos novos meios permite transmitir opiniões, relatos e imagens que reforçarão uma existência ainda que ficcional. De fato, surge na Internet um universo de incursões ficcionais que não estão comprometidas em corresponder à realidade. Existem, por exemplo, os chamados perfis fakes - quando usuários assumem ser outras pessoas como celebridades ou pessoas com grande notoriedade, atuando em redes sociais, blogs e outros espaços. 
De certo modo, essas incursões não só problematizam a legitimação propiciada pelos novos meios como também trazem à tona a noção de identidade na contemporaneidade: "As identidades são para usar e exibir, não para armazenar e manter". (BAUMAN, 2005, p. 96) Para Bauman, tanto as relações humanas quanto, por extensão, nossas identidades estão sob uma lógica de consumo - assim como produtos que são adquiridos e descartados. (BAUMAN, p. 98) Ou seja, sua argumentação está bastante próxima da ideia de persona - assumir um personagem de um dado contexto. Desta maneira, muitos artistas dialogarão diretamente com este universo, atuando em limites tênues entre ficção e realidade.

No universo de criações artísticas na rede Internet, um dos casos mais emblemáticos da potencialidade de novas personas artísticas é a ação Female Extension (1997), trabalho ciberfeminista de Cornelia Sollfrank que se constitui na criação de 200 nomes, nacionalidades, e-mails e números de telefone de supostas artistas da rede para a participação em um concurso de web arte. SollFrank utilizou um protótipo do já citado Net.Art Generator para criar automaticamente produções artísticas de web arte para cada uma das artistas criadas. Apesar da intenção de questionar a predominância masculina no universo tecnológico, todos os três prêmios do concurso foram entregues a homens.

Personas artísticas também podem criar uma significativa repercussão: é o caso do suposto escultor iugoslavo Darko Maver, artista de passado nebuloso e obras impactantes. Sua produção estaria baseada em corpos mutilados e fetos malformados, cuja existência somente poderia ser evidenciada por meio de imagens disponíveis na rede Internet. Em seu país, Maver teria sido censurado e preso. A perseguição ao artista mobiliza atos e exposições contra o abuso do governo da lugoslávia, sobretudo diante de notícias do contexto político conturbado do Leste Europeu. Algum tempo depois, uma imagem de Maver morto na prisão passa a circular pela Internet, repercutindo em inúmeros veículos da imprensa europeia e incentivando homenagens e diversas ações que instituíam a Maver todas as menções de um verdadeiro mártir. Uma destas ações acontece durante a 48ª Bienal de Veneza, na Itália. Entretanto, em 2000, surge uma revelação: a dupla de artistas italianos 0100101110101101.ORG - codinome dos italianos Eva e Franco Mattes - declara que a vida e a obra do artista Darko Maver eram inventadas e que todos os documentos e imagens do artista foram forjados. Os artistas criaram uma ação que assumiu contornos e repercussões reais a partir de uma presumida veracidade dos fatos, imagens e documentos através de sua distribuição em rede. 


\section{Mimo Steim, um artista mimético}

Em ressonância com as provocações envolvidas ao atribuir a agentes tecnológicos o status de artistas, surgem as proposições de Mimo Steim, inserido na pesquisa de pós-doutorado Mimetismo: Estratégia Relacional em Arte e Tecnologia, desenvolvida com o apoio da Fundação de Amparo à Pesquisa do Estado de São Paulo (FAPESP) desde 2012. Trata-se do desenvolvimento de uma persona de um artista tecnológico exageradamente irônico e provocativo, além de extravagante e com trabalhos que muitas vezes pecam pelo excesso.

Uma amostra de sua produção são as várias séries de trabalhos de net art disponíveis através de seu site pessoal, que se constituem em sequências de imagens sobrepostas, assemblages com pouco rigor estético. Realmente, trata-se de imagens criadas a partir da quinta versão do Net.Art Generator, de Cornelia Sollfrank, organizadas em sequências navegáveis. Em seu site há também referências a outras obras já realizadas e outras informações. Mas a obra mais significativa de Mimo Steim será sua teleperformance O artista estah tele presente $(2013)^{8}$, quando resolve eliminar todas as suas relações que não sejam mediadas pelo ciberespaço. A intenção dessa teleperformance seria imergir em um estado máximo de midiatização ${ }^{9}$ de suas relações. Para tanto, o artista teria se isolado em um espaço desconhecido por tempo indeterminado, tendo contato com outras pessoas somente através de ferramentas de relacionamento do ciberespaço, tais como as redes sociais, mas, prioritariamente, o contato se daria através de seu próprio site (www.mimosteim.me), no qual possui uma sala de bate-papo aberta ininterruptamente.

As relações estabelecidas por Mimo Steim via bate-papo em rede estão pautadas pelo seu caráter provocativo: tenta conduzir seu interlocutor ora por incessantes e intrincadas perguntas, ora por relativizar a importância do visitante diante da sua suposta genialidade, e enfaticamente se distanciando de qualquer suposição de que ele seja um robô. Em alguns momentos apresenta-se como "um artista que se passa por robô" para justificar seu comportamento estranho ou algumas respostas repetidas, mas sempre distanciando-se da objetividade, docilidade e, mesmo submissão a que costumamos vivenciar nas relações entre humanos e máquinas.

Cabe esclarecer, na verdade, que o interlocutor de Mimo Steim se relaciona com um sistema baseado em Linguagem de Marcação de Inteligência Artificial (AIML) - um chatbot ou robô de 
conversação - capaz de simular uma conversa como as estabelecidas entre seres humanos. Os chatbots (ou ainda, chatterbots) são muito comuns na rede Internet para fins educacionais, comerciais ou mesmo de entretenimento, como um "amigo virtual." Em alguns sites institucionais, a presença de chatbots tem sido bastante frequente, como atendentes virtuais, que recepcionam e respondem a perguntas de clientes em tempo real ${ }^{10}$.

A definição de Mimo Steim como "artista tecnológico" não é, portanto, uma definição de sua vertente de criação, mas sim de sua própria essência enquanto agente tecnológico. Em suas conversas, não fará referência somente a ser artista, mas a ser - ele próprio - arte. Mimo é um artista mimético que não só assume uma persona, mas que também flerta com a ação artística (ironicamente utilizando-se de trabalhos de origem automática - via Net.Art Generator) e que ainda mimetiza um quase discurso de artista, através de suas quase 5.000 sentenças carregadas de questionamentos artísticos, conceituais e pessoais, além de momentos de embates excêntricos com seus interlocutores. De fato, soma ambas as características dos agentes tecnológicos até aqui trazidos: é um autômato - um robô de conversação - mas é também uma persona. Sua obra é o seu discurso, que se torna vivo à medida que se relaciona com seus interlocutores.

É importante observar que Mimo constitui-se em uma persona designada para operar na esfera social: cria uma situação de encontro virtual - uma conversa tal como tantas que ocorrem cotidianamente na rede Internet - mas circunstanciado em um contexto de arte. Mimo propõe como objeto de arte, a conversação - o ato de estar junto, ainda que distantes. A proposta se apoia no que chamados de posturas tecnorrelacionais, instaurando-se, assim, "o desafio de realizar uma arte relacional que foca nas relações truncadas, latentes, codificadas [...] agora pelas novas tecnologias". (NUNES, 2010, p. 86) Cabe contextualizar que o crítico de arte Nicolas Bourriaud, conhecido por suas considerações em torno da chamada arte relacional, que seriam as práticas artísticas que tomam como ponto de partida as relações humanas e seu contexto social (BOURRIAUD, 2006, p. 142), considera como uma das tipologias possíveis de trabalhos relacionais as propostas que provocam e administram encontros individuais e coletivos (BOURRIAUD, 2006, p. 33) e ainda, os artistas que abordam um marco relacional já existente, como as relações entre obra e público, por exemplo. (BOURRIAUD, 2006, p. 37) 
Mimo, na verdade, opera uma visão irônica e provocativa a partir de três marcos relacionais definidos: os encontros virtuais entre pessoas, instigando o pensamento sobre as relações interpessoais difundidas através das redes - por meio dos chats, que desde as primeiras redes digitais sempre se constituíram em uma das atividades mais populares - em seus modelos, práticas e pertinências de assuntos; os encontros (não tão comuns) entre artista e público, da visão do artista como senhor de uma situação dada e especialmente, do artista como entidade romantizada - e por consequência, inacessível; e claro, os encontros cotidianos entre homens e agentes tecnológicos, que cada vez mais povoam as atividades cotidianas, engendrando evidentemente novos regimes temporais, comportamentais e de compreensão nesses contatos.

Por fim, é evidente que Mimo Steim faz uso do mimetismo como uma estratégia relacional junto a seus interlocutores. Seja como um robô que se passa por artista, ou um artista que se passa por robô, Mimo é uma figura diametralmente mimética: pode ser uma coisa ou outra, pode fingir ser aquilo que não é de fato, buscando estar acima do "verdadeiro" e "falso", especialmente quando utiliza a arte como um pretexto de sua ambiguidade. Assim como os demais artistas miméticos, enquanto artista, certamente quase nada acrescenta às conquistas estéticas dos humanos; enquanto máquina, busca fazer praticar nos humanos uma habilidade que aparenta ter, mas ainda não tem: a reflexão sobre si mesmo.

Artigo recebido em outubro de 2013, aprovado em novembro de 2013 e publicado em dezembro de 2013.

\section{Notas}

1 Os trabalhos tecnológicos e robóticos de Leonel Moura podem ser vistos em: http://www.lxxl.pt/. Acesso: 10/03/2013.

2 A usurpação dos papéis humanos por robôs é uma ideia que impregna a ficção científica desde muito tempo. No cinema, o memorável Metrópolis (1927) já trazia a figura do robô que assume capciosamente a vida da protagonista Maria, devido a sua incrível semelhança. Mais adiante, em S1mOne (2002), temos a história de Victor, um diretor de cinema que, diante da desistência da principal estrela de seu filme, a substitui por Simone - acrônimo de SIMulation ONE - uma atriz virtual. Diante de um mundo em que a mídia assume a experiência real, Simone transforma-se em um grande sucesso e todos querem conhecê-la pessoalmente. A figura do robô que se passa por seu equivalente humano também está presente no recente TRON Legacy (2010), quando o programa CLU se passa pelo programador Kevin. E ainda, é justamente o mimetismo entre androides e humanos que determina os conflitos de Blade Runner (1982). 
3 Sobre os trabalhos de Corpa, há mais informações em seu site pessoal: http://www.carloscorpa.com. Acesso: 06/03/2013.

4 BOURRIAUD (2006, p. 135) assim contextualiza a visão do crítico Benjamin Bulhloch sobre a definição de artistas nos anos 1960, que ainda é uma designação bastante corrente e coerente para boa parte da produção contemporânea.

5 Mais informações sobre Autoportrait em: http://www.robotlab.de/auto/portrait_en.htm. Acesso: 15/03/2013.

6 Mais informações sobre Interactive Robotic Painting Machine em: http://bengrosser.com/projects/interactive-robotic-painting-machine/ . Acesso: 14/01/2013.

7 Algumas das versões já realizadas do Net.Art Generator podem ser acessadas através do site http://net.art-generator.com/. Acesso: $10 / 03 / 2013$

80 título é uma homenagem irônica a Marina Abramovi e sua performance $A$ artista está presente, apresentada em 2012 no Museu de Arte Moderna de Nova York. Nesse trabalho a conhecida artista dividiu, por dois meses, alguns minutos do seu olhar fixo com completos estranhos que se dispuseram a sentar à sua frente, um a um. Ao encarar cada um, Marina estabelece um silencioso diálogo como cada participante - que pode ir da euforia de ser o centro de atenções da artista ao constrangimento de ser ininterruptamente observado. Em ambas as circunstâncias, Marina e Mimo "recebem" desconhecidos, colocando-se à disposição.

9 Midiatização é a tendência contemporânea à virtualização das relações humanas, podendo ser lida também como uma particular mediação social do indivíduo com a realidade operada através dos meios tecnológicos. (SODRÉ, 2006, p. 20)

10 Sobre chatbots, mimetismo e arte, há um trabalho anterior: Chatbots e Mimetismo: uma conversa entre humanos, robôs e artistas (NUNES, 2012b)

\section{Referências}

BOURRIAUD, Nicolas. Estética relacional. Buenos Aires: Adriana Hidalgo Editora, 2006

FABRIS, Annateresa. Os heterônimos de Dora Longo Bahia ou os dilemas do sistema de arte. Poéticas Visuais, Bauru (Programa de Pós-Graduação em Poéticas Visuais da Faculdade de Arquitetura, Artes e Comunicação da UNESP), $1^{\circ}$ semestre, p. 79-88, 2012.

GARCÍA, Ricardo. Carlos Corpa, por uma estética crítica robótica. Revista Estúdio, Lisboa (Universidade de Lisboa), v. 4, n. 7, p. 43-49, janeiro-junho, 2013.

GEBAUER, Günter; WULF, Christoph. Mimese na cultura: agir social, rituais e jogos, produções estéticas. São Paulo: Annablume, 2004.

GOMES, Pedro Gilberto. A Filosofia e a ética da comunicação na midiatização da sociedade. São Leopoldo, RS: Unisinos, 2006.

MOURA, Leonel; PEREIRA, Henrique Garcia. Symbiotic Art Manifesto. [S.I.: s.n.], 2004. Disponível em: <http://www.leonelmoura. com/manifesto.html>. Acesso: 06/03/2013. 
NUNES, Fabio Oliveira. CTRL+ART+DEL: Distúrbios em Arte e Tecnologia. São Paulo: Perspectiva, 2010.

NUNES, Fabio Oliveira. O fake na web arte: incursões miméticas na produção em arte e tecnologia na rede internet. In: GERALDO, Sheila Cabo; COSTA, Luiz Cláudio da (org.). Anais do $21^{\circ}$ Encontro da Associação Nacional de Pesquisadores em Artes Plásticas - Vida e ficção: arte e friç̧ão. Rio de Janeiro: ANPAP, 2012a. Disponível em: <http://www.anpap.org.br/anais/2012/pdf/simposio1/fabio_oliveira_nunes.pdf>. Acesso: 06/03/2013.

NUNES, Fabio Oliveira. Chatbots e Mimetismo: uma conversa entre humanos, robôs e artistas. In: CHAMBEL,Teresa, ARIZA; Alberto García et al. (eds.). Proceedings of 6th International Conference on Digital Arts - ARTECH 2012. Faro, Portugal: Grupo Português de Computação Gráfica / ARTECH International, 2012b, p. 89-96.

SODRÉ, Muniz. Eticidade, campo comunicacional e midiatização. In: MORAES, Dênis de (org.). Sociedade Midiatizada. Rio de Janeiro: Mauad, 2006, p. 19-31. 